\title{
Produção Arbórea e Animal em Sistema Silvipastoril com Acácia- negra (Acacia mearnsii)
}

\author{
Zélia Maria de Souza Castilhos(1), Raquel Santiago Barro(2), José Flores Savian ${ }^{(1)}$ e \\ Henrique Rogério Branco do Amaral(1)
}

(1)Fepagro, Gonçalves Dias, 570, CEP 90130-060, Porto Alegre-RS. E-mail: zelia.voy@terra.com.br; josé-savian@fepagro.rs.gov.br; henrique-amaral@fepagro.rs.gov.br; 2)Universidade Federal do Rio Grande do Sul - UFRG, Avenida Bento Gonçalves, 7712, CEP 91540000, Porto Alegre-RS. E-mail: raquel.barro@ufrgs.br

\begin{abstract}
Resumo - Com o objetivo de avaliar o desempenho dos componentes arbóreo e animal em um sistema silvipastoril (SSP) com acácia-negra (Acacia mearnsii De Wild) e gramíneas perenes de verão, foi conduzido um trabalho em convênio com a empresa Seta S.A., na unidade da Fepagro em Tupanciretã, RS, no período de outubro de 1995 a maio de 2003. O delineamento experimental foi um bifatorial (espécie forrageira e densidade arbórea) inteiramente casualizado, com duas repetições. As espécies forrageiras (EF) avaliadas foram capim annoni (Eragrostis plana), braquiária (Brachiaria brizantha) e capim gatton (Panicum maximum $\mathrm{cv}$. Gatton) nos quatro primeiros anos, e capim gatton, capim aruana (P. maximum cv. Aruana) e capim pangola (Digitaria diversinervis) para os demais anos. As densidades arbóreas (DA) testadas foram de 1.667, 1.000, 833 e 500 árvores.ha $^{-1}$. Com 1.667 árvores.ha $^{-1}$ houve maior rendimento de madeira em todas as avaliações, não diferindo de 1.000 árvores/ ha $^{-1}$ a partir do quinto ano. A produtividade animal foi mais elevada em DA de 833 e 500 árvores.ha ${ }^{-1}$, sendo respectivamente 229 e $223 \mathrm{~kg} \cdot \mathrm{ha}^{-1}$ de peso vivo. Aos sete anos de implantação da acácia negra, o volume de madeira foi de 166; 143; 86 e $51 \mathrm{~m}^{3}$.ha ${ }^{-1}$, respectivamente, nas densidades arbóreas de 1.667; 1.000; 833 e 500 árvores.ha ${ }^{-1}$. Para que haja um equilíbrio entre produção arbórea e animal, SSPs com densidades arbóreas entre 1.000 e 833 árvores.ha ${ }^{-1}$ apresentam-se como alternativas viáveis para os produtores rurais.
\end{abstract}

Termos para indexação: Sistema agroflorestal, produção animal, Panicum maximum, gramíneas perenes, pastagem, Digitaria diversinervis.

\section{Trees and Animal Production in a Silvipastoral System with Black Wattle (Acacia mearnsii)}

\begin{abstract}
A silvopastoral study consisting of black wattle (Acacia mearnsii De Wild) and tropical perennial grasses was developed at the Fepagro Research Unity in Tupanciretã, RS, in collaboration with Seta Group, from October 1995 until May 2003, with the objective of evaluating trees and animal (beef cattle) performances. The experiment was a bifactorial completely randomized design (forage specie and arboreal density) with two replications. The forage species assessed (FS) were anonni grass (Eragrostis plana), signal grass (Brachiaria brizantha) and gatton panic (Panicum maximum cv. Gatton) in the first four years, and gatton panic, aruana grass (Panicum maximum cv. Aruana) and pangola grass (Digitaria diversinervis) in the remaining years. Trees densities (TD) tested were of 1,$667 ; 1,000 ; 833$ and 500 trees.ha $^{-1}$. The highest wood production was observed at TD 1,667 trees.ha-1 ${ }^{-1}$, although it was not different from that for 1,000 trees.ha-1 from the fifth year on. The animal production under arboreal density 833 and 500 trees.ha $^{-1}$ was 229 e $223 \mathrm{~kg} \cdot \mathrm{ha}^{-1}$ of liveweight gain, respectively. At seven years of cultivation of black wattle the wood production were $166 ; 143 ; 86$ and $51 \mathrm{~m}^{3} / \mathrm{ha}^{-1}$, respectively, under arboreal density of 1,667;1,000; 833 and 500 trees.ha $^{-1}$. To achieve of an equilibrium between trees and animal production, this study showed that silvopastoral systems with 1,000 and 833 trees.ha-1 ${ }^{-1}$ are viable alternatives for farmers.
\end{abstract}

Index terms: Agroforestry system, animal production, Panicum maximum, perennial grasses, forages, Digitaria diversinervis.

\section{Introdução}

Há no mundo uma demanda crescente por produtos de base florestal e pecuária. No Brasil isto se reflete no crescimento contínuo das exportações de produtos oriundos das florestas plantadas e da produção animal.

Os produtos florestais brasileiros são considerados altamente competitivos no mercado internacional, de 
tal forma que as exportações do setor em 2005 foram de US\$ 7,4 bilhões, correspondendo a $6,3 \%$ do total exportado pelo país, superado apenas pelos complexos soja e carnes (ABRAF, 2006). Por outro lado, o Brasil tem o maior rebanho bovino comercial do mundo. No ano de 2005, foram abatidas mais de 40 milhões de cabeças, sendo exportados US\$ 3,5 milhões, o que representou um crescimento de $20 \%$ nos últimos oito anos; neste contexto, a pecuária de corte no Rio Grande do Sul contribuiu com $14 \%$ do total de bovinos abatidos no Brasil (PASTRELLO, 2006).

A atividade pecuária tem inquestionável importância econômica e social no Rio Grande do Sul, apesar de seus índices produtivos estarem muito aquém do desejado: a média anual de produtividade bovina na exploração extensiva, com base principalmente nas pastagens naturais, é da ordem de 60 a $90 \mathrm{~kg} / \mathrm{ha}$ de peso vivo, sem o uso de tecnologias expressivas. A pesquisa apresenta alternativas de manejo que permitem um forte incremento da produtividade de carne, leite e lã, produzidos a pasto. Conforme foi demonstrado, no diagnóstico da pecuária de corte do Rio Grande do Sul (SEBRAE/SENAR/FARSUL, 2006), a maior eficiência econômica da atividade no estado se dá em sistemas associados à produção vegetal. Caso contrário, ocorre uma forte dependência do ingresso de "rendas não agrícolas" na propriedade. Em virtude disto, as áreas destinadas à produção animal vêm sendo substituídas por atividades que proporcionam maior renda ao produtor. Estima-se que cerca de 4,7 milhões de hectares de campos nativos nos últimos 35 anos foram convertidos em lavouras e, mais recentemente, em florestas plantadas (JACQUES e NABINGER, 2006). O crescimento da silvicultura também se deve ao fato de que as atividades de base florestal encontram na região Sul do Brasil nichos de elevada produtividade, devido à excelência em condições edafo-climáticas para o desenvolvimento desta atividade.

Neste contexto, a adoção de sistemas integrados, tais como sistemas silvipastoris (SSP), representa uma forma de uso da terra na qual as atividades silviculturais e pecuárias são combinadas para gerar produção de forma complementar pela interação dos seus componentes (GARCIA; COUTO, 1997). Esses sistemas permitem melhor eficiência de aproveitamento dos recursos naturais e constituem-se em uma das melhores alternativas para alcançar maior produtividade, por meio do uso mais sustentável da terra. Além do quesito produtividade, a utilização de SSP visa maior sustentabilidade ambiental à medida que propõe uma exploração menos intensiva das espécies florestais, principalmente no que tange à utilização de densidades arbóreas menores, fator-chave ao planejamento e uso destes sistemas. Além disso, a atividade florestal não apresenta retorno financeiro rápido. Desse modo, sistemas agrossilvipastoris podem ser uma alternativa viável para se obter uma renda extra dentro de um prazo inferior ao que se teria somente com a exploração florestal. Além disso, estes sistemas contribuem para minimizar os custos de implantação da floresta (GARCIA; COUTO 1991; MELO, 1991).

A acácia-negra, por apresentar uma expressiva área cultivada no Rio Grande do Sul (156.377 ha), em torno de $87 \%$ da área total plantada com esta espécie no Brasil (ABRAF, 2006), apresenta-se como uma excelente opção para compor sistemas silvipastoris, principalmente, pela capacidade de fixar nitrogênio da atmosfera. $\mathrm{O}$ cultivo desta espécie florestal é realizado basicamente na pequena e média propriedade, apresentando um relevante papel socioeconômico e ecológico. A importância econômica se reflete na integração entre o homem do campo e a indústria, contribuindo na redução do êxodo rural. Direta ou indiretamente, cerca de $40 \mathrm{mil}$ famílias são beneficiadas pelas alternativas criadas pelo cultivo da acácia-negra (MANTOEFEL, 1991).

A adoção de SSP no Rio Grande do Sul ainda é pouco expressiva, embora exista um apreciável acervo de informações científicas sobre a viabilidade da integração entre a atividade florestal e a produção de carne. Nos últimos anos, a pesquisa em SSP concentrou seus esforços no estudo de diferentes densidades arbóreas com eucalipto (Eucalyptus spp.) e com acácia-negra sobre o rendimento da forragem e a produtividade de bovinos e ovinos em pastejo (SAIBRO, 2001; LUCAS, 2004), incluindo estudos sobre os efeitos da densidade arbórea, raleio, introdução de espécies forrageiras de inverno ou de verão e níveis de oferta de forragem, resposta de bovinos e ovinos, produtividade florestal, ciclagem de nutrientes e estudos micrometeorológicos dentro do sub-bosque.

Objetivando maior eficiência energética e conservação ambiental, mais estudos devem ser desenvolvidos para o aprimoramento dos sistemas de produção, com menor dispêndio de insumos industrializados, além de redução da relação custo/beneficio em níveis competitivos através do aproveitamento racional dos processos biológicos e dos recursos naturais renováveis. A utilização de 
sistemas integrados (agrossilvipastoris) representa um novo desafio para o avanço das pesquisas nessa área. São necessários mais estudos, principalmente quanto ao uso de populações florestais adequadas, espécies arbóreas e forrageiras adaptadas, e as diversas possibilidades de integração agroflorestais e/ou silvipastoris assim como, manejo e interações entre os componentes do sistema.

Baseado nestas questões, foi desenvolvido o presente estudo, com o objetivo de avaliar o desempenho dos componentes arbóreo e animal em um sistema silvipastoril com acácia-negra e gramíneas perenes de verão.

\section{Material e Métodos}

O estudo foi conduzido, em convênio com a empresa SETA S.A. na unidade da Fundação Estadual de Pesquisa Agropecuária (Fepagro), em Tupanciretã, RS, no período de outubro de 1995 a maio de 2003.

O solo da área experimental é um argissolo vermelho amarelo, textura média, relevo ondulado e substrato arenito (SISTEMA..., 1999).

O clima da região é subtropical úmido (Cfa), com verões quentes, segundo a classificação de Köppen. Apresenta temperaturas médias de $19,4^{\circ} \mathrm{C}$ com mínima absoluta de $-5,1{ }^{\circ} \mathrm{C}$ e máxima de $42,6^{\circ} \mathrm{C}$. A precipitação anual é superior a $1.300 \mathrm{~mm}$ e inferior a $1.800 \mathrm{~mm}$, com regime de chuvas hibernais (MACHADO, 1950; MORENO, 1961).

O delineamento experimental utilizado foi um bifatorial (espécies forrageiras e densidade arbórea) inteiramente casualizado, com duas repetições. As espécies forrageiras (EF) avaliadas foram Eragrostis plana (capim annoni), Brachiaria brizantha (braquiária) e Panicum maximum cv. Gatton (capim gatton) nos quatro primeiros anos, e capim gatton, Panicum maximum cv. Aruana (capim aruana) e Digitaria diversinervis (capim pangola) para os demais anos. As densidades arbóreas (DA) testadas inicialmente até o quarto ano foram, 1.667 e 1.000 árvores.ha ${ }^{-1}$, obtidas com espaçamentos de $3 \mathrm{mx}$ $2 \mathrm{~m}$ e $5 \mathrm{~m}$ x $2 \mathrm{~m}$, respectivamente (entre linhas x dentro das linhas). A partir do quinto ano e após a realização de desbastes, as densidades arbóreas foram reduzidas para $833(6 \mathrm{~m} \times 2 \mathrm{~m})$ e 500 árvores.ha-1 $(10 \mathrm{~m} \times 2 \mathrm{~m})$, obtidas pela supressão intercalada de uma linha nas densidades originais.

A área experimental era constituída por 12 potreiros, com áreas variando de 0,93 ha a 2,75 ha, perfazendo um total de 16 ha. A acácia-negra foi estabelecida em duas densidades de plantas em outubro de 1995. Para o estabelecimento da acácia-negra na área de capim annoni, espécie invasora predominante na região, foi realizado o preparo do solo (aração e gradagem) somente na linha de plantio. Nas áreas das demais pastagens cultivadas o preparo foi em toda a área.

A semeadura de capim gatton foi realizada na primavera de 1996 e da braquiária em fevereiro de 1998, mediante o preparo convencional do solo (aração e gradagem), utilizando-se uma densidade de sementes de $15 \mathrm{~kg} \cdot \mathrm{ha}^{-1}$.

No período de 8 de novembro de 2002 a 10 de janeiro de 2003, foi avaliada a radiação fotossinteticamente ativa nos diferentes espaçamentos de acácia negra, tendo como sub-bosque o capim aruana. Os dados foram coletados através de sensores acoplados a um "datalogger" (modelo CR10x, Campbell Scientific, Logan, EUA).

Os tratamentos que utilizaram menores densidades arbóreas permitiram maior penetração de luz solar na pastagem e, portanto, representaram os maiores valores de radiação fotossinteticamente ativa, ou seja, no comprimento de onda absorvido pelas plantas. Os valores obtidos no trabalho são um percentual em relação à radiação fotossinteticamente ativa observada a pleno sol. Nas maiores densidades arbóreas utilizadas, houve uma redução na radiação fotossinteticamente ativa na ordem de $50 \%$, em relação às menores densidades avaliadas: Nas densidades 1.667 e 1.000 árvores.ha ${ }^{-1}$ (espaçamentos $3 \mathrm{~m} \times 2 \mathrm{~m}$ e $5 \mathrm{~m} \times 2 \mathrm{~m}$ ) foram obtidas leituras de $15 \%$ e $19 \%$ da radiação, respectivamente, quando comparado às leituras fora da mata. Já nas menores densidades avaliadas (833 e 500 árvores.ha ${ }^{-1}$ ), os valores obtidos foram da ordem de $32 \%$ e $40 \%$, respectivamente, em relação a pleno sol.

Como o capim annoni não suportou o sombreamento a partir do terceiro ano de crescimento do estrato arbóreo, desaparecendo dos potreiros, em janeiro de 2001, em seu lugar, foi estabelecida por mudas uma pastagem de capim pangola. Verificou-se também a partir do terceiro ano, uma redução muito expressiva na população de plantas de braquiária, provavelmente em função das baixas temperaturas ocorridas durante o inverno. Assim, em outubro de 2001, os potreiros outrora semeados com essa espécie foram semeados com capim aruana, numa densidade de $15 \mathrm{~kg} \cdot \mathrm{ha}^{-1}$ de sementes.

As pastagens foram adubadas anualmente, na primavera, com $300 \mathrm{~kg} \cdot \mathrm{ha}^{-1}$ da fórmula 5-20-20 (NPK) e $200 \mathrm{~kg} \cdot \mathrm{ha}^{-1}$ de uréia. 
As estimativas dendrométricas foram realizadas, anualmente, através de inventário florestal com amostragem aleatória simples, em quatro repetições por tratamento e em parcelas de $15 \mathrm{~m}$ x $20 \mathrm{~m}$. As variáveis medidas foram o diâmetro à altura do peito (DAP) e a altura comercial (distância do solo até a inserção dos ramos da copa). Após as medidas, foram definidos os centros de classe de diâmetro e abatidas às árvores, dentro dos centros de classe, as quais foram cubadas pelo método de Smalian, totalizando em média $10 \%$ das árvores da parcela. As demais alturas foram estimadas por regressão, bem como o volume comercial por hectare (Tabela 1).

Tabela 1. Modelos empregados para estimar altura (h) e volume comercial (V).

\begin{tabular}{lccccc}
\hline \multicolumn{1}{c}{ Modelo } & $\mathbf{R}^{\mathbf{2}}$ & Erro padrão & $\mathbf{b}_{\mathbf{0}}$ & $\mathbf{b}_{\mathbf{1}}$ & Finalidade \\
\hline $\log \mathrm{h}=\mathrm{b}_{0}+\mathrm{b}_{1}{ }^{*} 1 / \mathrm{d}$ & 0,925 & 0,044 & 0,9478 & $-1,082$ & Altura $-\mathrm{m}$ \\
$\mathrm{V}=\mathrm{b}_{0}+\mathrm{b}_{1} * \mathrm{~d}^{2}$ & 0,982 & 0,0029 & $-0,0015$ & 0,00043 & ${\text { Volume }-\mathrm{m}^{3} / \mathrm{c}}^{3}$ \\
\hline
\end{tabular}

Fonte: Modelos usados pela empresa Seta S.A.

A produção de casca foi estimada através da equação:

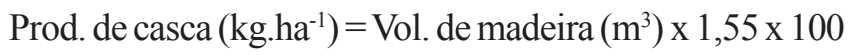

Os modelos matemáticos para estimativa da relação hipsométrica e do volume apresentaram altos coeficientes de determinação e baixos erros padrão, que conferem consistência às estimativas do inventário florestal.

A produção animal, medida através do ganho médio diário dos novilhos (raça Bradford com um ano de idade e peso médio inicial de $180 \mathrm{~kg}$ ) e ganho de peso vivo por área, foi avaliada nos períodos de 09 de setembro de 2002 a 13 de novembro de 2002 e de 22 de janeiro de 2003 a 11 de abril de 2003, somente nas densidades arbóreas de 833 e 500 árvores.ha ${ }^{-1}$. O método de pastejo utilizado foi o contínuo com carga variável (MOTT; LUCAS, 1952), ajustado para manter a oferta de forragem de $12 \%$ (12 kg de matéria seca por $100 \mathrm{~kg}$ de peso vivo por dia). Foram empregados quatro animais "testes" ou permanentes por potreiro e um número variável de animais reguladores, que eram colocados ou retirados dos potreiros com a finalidade de manter ajustado o nível de oferta de forragem desejado, conforme disponibilidade de forragem (taxa de acúmulo diária, acrescida da massa de forragem disponível diariamente no período de pastejo projetado).

Todos os animais que entravam no experimento ou dele saíam eram pesados previamente, havendo um desjejum prévio de $12 \mathrm{~h}$ em cada período de pastejo. $\mathrm{O}$ ajuste de carga animal era realizado a cada quatro semanas.

O ganho de peso médio diário dos animais "testes" foi obtido pela diferença entre as pesagens realizadas no final e início de cada período de pastejo, dividido pelo número de dias que os animais permaneceram em pastejo na área. As pesagens intermediárias auxiliaram no ajuste da carga animal em função da oferta de forragem pretendida e no controle do desempenho animal.

$\mathrm{O}$ ganho de peso por área $\left(\mathrm{kg} \cdot \mathrm{ha}^{-1}\right)$ foi obtido multiplicando-se o ganho médio diário pelo número de animais dia.ha ${ }^{-1}$, sendo esse, por sua vez, calculado pela contagem do número de animais que permaneciam no potreiro, em cada dia, multiplicado pelo número de dias de avaliação em cada período.

Os animais foram vacinados contra febre aftosa e carbúnculo hemático e sintomático e dosados a cada 4045 dias com vermífugos de amplo espectro (Ivermectina e Doramectina, alternadamente), e receberam controle permanente contra ectoparasitoses. Aágua foi fornecida aos animais em tanques de concreto com capacidade para $80 \mathrm{~L}$, regulada por meio de boias em cada tanque e potreiro, sendo esta canalizada de um reservatório central.

A análise da variância e teste $\mathrm{F}$, em cada avaliação, foi realizada considerando-se os efeitos de espécies forrageiras e densidades arbóreas com fixos. Para os casos onde houve efeito significativo dos efeitos principais de espécies forrageiras e densidades arbóreas ou da interação espécies $\mathrm{x}$ densidade foi feita a comparação das médias dos tratamentos pelo teste de Tukey, em nível de 5\% de probabilidade de erro.

As análises estatísticas foram realizadas, com o auxílio do programa computacional Genes (CRUZ, 2001).

\section{Resultados e Discussão}

A produção volumétrica de madeira e a produção de casca do componente florestal foram afetadas 
significativamente $(\mathrm{P}<0,05)$ pela densidade arbórea, independentemente do ano de avaliação (Tabela 2). Observa-se que a partir do desbaste (ano 2000), houve uma clara diferenciação entre os indicadores volume de madeira e peso de casca nas diferentes densidades arbóreas avaliadas. Entre os anos 2000 a 2002, a produção florestal nas menores densidades arbóreas, 833 e 500 árvores ha $^{-1}$, representou aproximadamente a metade dos valores obtidos para as densidade de 1.667 e 1.000 árvores.ha ${ }^{-1}$.

Tabela 2. Volume de madeira $\mathrm{em}^{3}$.ha $\mathrm{ha}^{-1}$ e peso de casca em $\mathrm{kg} /$ ha de acácia-negra em quatro densidades arbóreas e sete anos de avaliação, em Tupanciretã, RS, considerando médias de cinco espécies forrageiras e duas repetições.

\begin{tabular}{|c|c|c|c|c|c|c|c|}
\hline \multirow{2}{*}{$\begin{array}{c}\text { Densidades } \\
\text { arbóreas (DA) } \\
(\text { árvores.ha-1) }\end{array}$} & \multicolumn{7}{|c|}{ Ano de avaliação } \\
\hline & 1996 & 1997 & 1998 & 1999 & 2000 & 2001 & 2002 \\
\hline & \multicolumn{7}{|c|}{ Volume } \\
\hline DA1 (1667) & $1,9^{\mathrm{ns}}$ & $22 \mathrm{a}$ & $67^{\mathrm{ns}}$ & $107 \mathrm{a}$ & $120 \mathrm{a}$ & $143 \mathrm{a}$ & $166 \mathrm{a}$ \\
\hline DA2 (1000) & 1,6 & $15 \mathrm{~b}$ & 59 & $87 \mathrm{~b}$ & $109 \mathrm{a}$ & $128 \mathrm{a}$ & $143 \mathrm{ab}$ \\
\hline DA3 (833) & & & & & $55 \mathrm{~b}$ & $81 \mathrm{~b}$ & $86 \mathrm{bc}$ \\
\hline \multirow[t]{2}{*}{ DA4 (500) } & & & & & $39 \mathrm{~b}$ & $56 \mathrm{~b}$ & $51 \mathrm{c}$ \\
\hline & \multicolumn{7}{|c|}{ Casca } \\
\hline DA1 (1667) & $299^{\mathrm{ns}}$ & 3389 a & $10401^{\text {ns }}$ & $16.612 \mathrm{a}$ & $18.650 \mathrm{a}$ & $22.162 \mathrm{a}$ & $25.711 \mathrm{a}$ \\
\hline DA2 (1000) & 253 & $2315 b$ & 9190 & $13.540 \mathrm{~b}$ & $16.878 \mathrm{a}$ & $19.812 \mathrm{a}$ & $22.189 \mathrm{ab}$ \\
\hline DA3 (833) & & & & & $8.563 \mathrm{~b}$ & $12.578 \mathrm{~b}$ & $13.402 \mathrm{bc}$ \\
\hline DA4 (500) & & & & & $5.986 \mathrm{~b}$ & $8.659 \mathrm{~b}$ & $7.973 \mathrm{c}$ \\
\hline
\end{tabular}

Médias de tratamentos seguidas de mesma letra, na coluna, não diferem ao nível de $5 \%$ de probabilidade pelo teste de Tukey. ${ }^{\text {ns }}=$ não significativo.

A produtividade florestal volumétrica de madeira expressa pelo incremento médio anual (IMA) no período de 7 anos foi de $23,71 \mathrm{~m}^{3}{ }_{\text {cc }} / \mathrm{ha} /$ ano na densidade de 1.667 e de $20,43 \mathrm{~m}^{3}{ }_{\text {cc }} / \mathrm{ha} /$ ano na densidade de 1.000 árvores. $\mathrm{ha}^{-1}$. Na segunda etapa do trabalho, após a intervenção de desbaste, a produtividade foi avaliada, após o quarto ano, pelo incremento periódico anual (IPA), tendo o seguinte comportamento: (1) $15,33 \mathrm{~m}^{3}$ / $/$ ha/ano para 1.667 ; (2) $11,33 \mathrm{~m}^{3}{ }_{\mathrm{cc}} \cdot \mathrm{ha}^{-1} \cdot$ ano $^{-1}$ para $1.000 ;$ (3) $10,33 \mathrm{~m}^{3}{ }_{\mathrm{cc}} \cdot \mathrm{ha}^{-1} \cdot$ ano $^{-1}$ para 833, e; (4) 4,0 $\mathrm{m}^{3}$ cc $/ \mathrm{ha} /$ ano para 500 árvores.ha ${ }^{-1}$. Estes resultados revelam que o peso do desbaste de $50 \%$ afetou a maximização da produção volumétrica florestal. Estes resultados estão de acordo com observações de Schneider et al. (2000), os quais esclarecem que a produção de madeira e casca verde por área de acácianegra apresenta uma relação direta com o espaçamento de plantio. No menor espaçamento avaliado ( $1 \mathrm{mx} 1 \mathrm{~m})$, a produtividade de madeira com casca foi maior (261 $\mathrm{m}^{3}$.ha-1) em relação aos espaçamentos de $3 \mathrm{~m} \times 1,33 \mathrm{~m}$ e $3 \mathrm{~m} \times 2 \mathrm{~m}$, porém com menor diâmetro médio e maior mortalidade das árvores.
Por outro lado, Clason (1999) demonstrou que práticas de manejo florestal e da pastagem usadas em uma plantação comercial de Pinus taeda aumentaram a produção de madeira. Glufke et al. (1997) e Schneider et al. (1999) esclarecem que o manejo florestal exerce grande influência sobre a produtividade silvícola, de forma que desbastes e desramas aplicados em momentos estratégicos com intensidades adequadas propiciam maiores rendimentos de madeira, principalmente quando se preconiza a obtenção de troncos com diâmetros maiores. No presente estudo, a redução na produtividade florestal pode ser atribuída ao desbaste e a queda de árvores que ocorreu após o desbaste.

Não foi constatada interação $(\mathrm{P}>0,05)$ entre o componente arbóreo e as espécies forrageiras. Em relação à influência do substrato herbáceo sobre o componente arbóreo, foi verificada diferença significativa $(\mathrm{P}<0,05)$ para as diferentes espécies forrageiras sobre as variáveis volume e peso de casca, apenas no quarto ano (1999) de avaliação (Tabela 3). O maior volume de madeira (103 $\mathrm{m}^{3}$.ha $\mathrm{a}^{-1}$ ) foi observado com o sub-bosque composto por capim gatton, não diferindo do obtido com sub-bosque de braquiária $\left(98 \mathrm{~m}^{3} \cdot \mathrm{ha}^{-1}\right)$. 
Tabela 3. Volume de madeira em $\mathrm{m}^{3} \cdot \mathrm{ha}^{-1}$ e peso de casca em kg.ha-1 de acácia-negra sobre diferentes sub-bosques forrageiros em sete anos de avaliação, em Tupanciretã, RS, considerando médias de duas densidades arbóreas e duas repetições.

\begin{tabular}{|c|c|c|c|c|c|c|c|}
\hline \multirow{2}{*}{$\begin{array}{l}\text { Espécies } \\
\text { forrageiras }\end{array}$} & \multicolumn{7}{|c|}{ Ano de avaliação } \\
\hline & 1996 & 1997 & 1998 & 1999 & 2000 & 2001 & 2002 \\
\hline & \multicolumn{7}{|c|}{ Volume } \\
\hline Eragrostis plana & $2,1 \mathrm{~ns}$ & $18^{\mathrm{ns}}$ & $58^{\mathrm{ns}}$ & $90 \mathrm{~b}$ & $74^{\mathrm{ns}}$ & & \\
\hline Brachiaria brizantha & 1,8 & 19 & 66 & $98 \mathrm{ab}$ & 86 & & \\
\hline P. Maximun cv. Gatton & 1,4 & 18 & 66 & $103 \mathrm{a}$ & 82 & $102^{\mathrm{ns}}$ & $109^{\mathrm{ns}}$ \\
\hline P. Maximun cv. Aruana & & & & & & 105 & 120 \\
\hline \multirow[t]{2}{*}{ Digitaria diversinervis } & & & & & & 100 & 105 \\
\hline & \multicolumn{7}{|c|}{ Peso de casca } \\
\hline Eragrostis plana & $332^{\mathrm{ns}}$ & 2.790 ns & $9012^{\text {ns }}$ & $13.993 \mathrm{~b}$ & $11.451^{\mathrm{ns}}$ & & \\
\hline Brachiaria brizantha & 279 & 2.914 & 10.165 & $15.221 \mathrm{ab}$ & 13.364 & & \\
\hline P. maximum cv. Gatton & 216 & 2.852 & 10.209 & $16.015 \mathrm{a}$ & 12.742 & $15.734^{\mathrm{ns}}$ & 16.932 ns \\
\hline P. maximum cv. Aruana & & & & & & 16.248 & 18.676 \\
\hline Digitaria diversinervis & & & & & & 15.426 & 16.348 \\
\hline
\end{tabular}

Médias de tratamentos seguidas de mesma letra, na coluna, não diferem ao nível de $5 \%$ de probabilidade pelo teste de Tukey. ${ }^{\text {ns }}=$ não significativo.

Alguns trabalhos indicam que o substrato forrageiro exerce influência sobre o crescimento das árvores. Peri et al. (2002), em trabalho realizado em Canterbury, Nova Zelândia, visando quantificar o efeito da presença de vegetação herbácea (sub-bosque) no crescimento e qualidade da madeira de $P$. radiata produzida em sistema silvipastoril, avaliaram um povoamento florestal estabelecido na densidade de 1.000 árvores.ha ${ }^{-1}$, submetido a práticas silviculturais (desbastes e desramas) até os sete anos de idade das árvores, resultando na densidade de 200 árvores.ha-1 ${ }^{-1}$ Aos dez anos de idade, não foram detectadas diferenças expressivas na altura das árvores entre os sub-bosques avaliados, porém a área basal das árvores foi influenciada negativamente pela presença de vegetação herbácea. O tratamento com solo desnudo apresentou área basal média 35\% maior do que os tratamentos com sub-bosque compostos por alfafa e gramíneas. Entretanto, os autores reportaram um efeito positivo da presença de alfafa no sub-bosque sobre a forma das árvores, sendo que nessa condição foi reportada a ocorrência de árvores com tronco mais cilíndrico do que na condição de solo desnudo.

O uso de desbastes em SSP pode, dependendo do grau de intensidade, diminuir a produção final de madeira, mas tem o propósito primordial de proporcionar maior entrada de luz no interior do sub-bosque e permitir ao componente forrageiro elevação da produtividade e, consequentemente, melhor desempenho animal.
Os tratamentos que utilizaram menores densidades arbóreas permitiram maior penetração de luz solar ao nível da pastagem e, portanto, representaram os maiores valores de radiação fotossinteticamente ativa, ou seja, no comprimento de onda absorvido pelas plantas. Os valores obtidos no trabalho são um percentual em relação à radiação fotossinteticamente ativa observada a pleno sol. Nas maiores densidades arbóreas utilizadas, houve uma redução na radiação fotossinteticamente ativa na ordem de $50 \%$, em relação às menores densidades avaliadas: Nas densidades 1.667 e 1.000 árvores.ha ${ }^{-1}$ (espaçamentos $3 \mathrm{mx}$ $2 \mathrm{~m}$ e $5 \mathrm{~m}$ x $2 \mathrm{~m}$ ) foram obtidas leituras de $15 \%$ e $19 \%$ da radiação, respectivamente, quando comparado às leituras fora da mata. Já nas menores densidades avaliadas (833 e 500 árvores.ha $^{-1}$ ), os valores obtidos foram da ordem de $32 \%$ e $40 \%$, respectivamente, em relação a pleno sol.

Os dados de produção animal estão apresentados em duas épocas distintas de avaliação, Período 1, que compreende a 65 dias de pastejo (de 09 de setembro de 2002 a 13 de novembro de 2002) e Período 2, com 79 dias de pastejo (de 22 de janeiro de 2003 a 11 de abril de 2003).

No primeiro período de avaliação, a produção animal (kg.ha-1 de peso vivo) observada não foi afetada significativamente $(\mathrm{P}>0,05)$ pelas espécies forrageiras ou densidades arbóreas, nem pela interação entre esses fatores (Tabelas 4 e 5). A produção animal foi de $87 \mathrm{~kg} \cdot \mathrm{ha}^{-1}$, média das espécies forrageiras e densidades 
arbóreas avaliadas. Neste período, também não foram verificadas diferenças importantes em termos da carga animal suportada pela pastagem sob as diferentes densidades arbóreas (Tabela 4). Por outro lado, o ganho médio diário (GMD) dos animais foi maior $(\mathrm{P}<0,05)$ na pastagem de capim pangola (Tabela 4), indicando que a pastagem composta por esta espécie forrageira, em subbosque de acácia negra, apresenta atributos que otimizam o desempenho individual dos animais. O capim gatton, nesse período de avaliação, não pode expressar seu potencial uma vez que a pastagem se encontrava com uma grande quantidade de material senescente, de baixo valor nutritivo, resultando numa performance animal aquém do esperado. Em contrapartida, na avaliação seguinte, quando essa pastagem estava com idade de rebrote menor (em torno de 60 dias), o desempenho animal foi otimizado, superando inclusive a capim pangola.

Tabela 4. Desempenho animal em sistema silvipastoril com gramíneas perenes de verão e acácia negra, considerando médias de duas densidades arbóreas e duas repetições. Tupanciretã, RS. Período 1: 09 de setembro de 2002 a 13 de novembro de 2002, Período 2: 22 de janeiro de 2003 a 11 de abril de 2003.

\begin{tabular}{|c|c|c|c|c|c|c|}
\hline \multirow[b]{2}{*}{ Espécies forrageiras } & \multicolumn{3}{|c|}{ Período 1} & \multicolumn{3}{|c|}{ Período 2} \\
\hline & $\begin{array}{c}\text { GMD } \\
\mathrm{kg}^{-1} \cdot \operatorname{animal}^{-1} \cdot \mathrm{dia}^{-1}\end{array}$ & $\begin{array}{c}\text { CA } \\
\text { kg.ha- }\end{array}$ & $\underset{\text { kg.ha }}{\mathbf{G A}}$ & $\begin{array}{c}\text { GMD } \\
\mathrm{kg}^{-1} \cdot \operatorname{animal}^{-1} \cdot \mathrm{dia}^{-1}\end{array}$ & $\begin{array}{c}\text { CA } \\
\text { kg.ha- }\end{array}$ & $\begin{array}{c}\text { GA } \\
\mathrm{kg} \cdot \mathrm{ha}^{-1}\end{array}$ \\
\hline P. maximum cv. Gatton & $0,447 b^{*}$ & $354 \mathrm{a}$ & $70 \mathrm{a}$ & $0,763 \mathrm{a}$ & $522 \mathrm{~b}$ & $133 \mathrm{a}$ \\
\hline P. maximum cv. Aruana & $0,538 \mathrm{~b}$ & $450 \mathrm{a}$ & $80 \mathrm{a}$ & $0,755 \mathrm{a}$ & $670 \mathrm{a}$ & $149 \mathrm{a}$ \\
\hline Digitaria diversinervis & $0,723 \mathrm{a}$ & $430 \mathrm{a}$ & $111 \mathrm{a}$ & $0,737 \mathrm{a}$ & $582 \mathrm{ab}$ & $137 \mathrm{a}$ \\
\hline
\end{tabular}

Médias seguidas por letras diferentes, na coluna, diferem ao nível de 5\% de probabilidade pelo teste de Tukey.

Tabela 5. Desempenho animal em sistema silvipastoril com gramíneas perenes de verão em duas densidades arbóreas de acácia negra, considerando médias de três espécies forrageiras e duas repetições, em Tupanciretã, RS. Período 1: 09 de setembro de 2002 a 13 de novembro de 2002, Período 2: 22 de janeiro de 2003 a 11 de abril de 2003.

\begin{tabular}{|c|c|c|c|c|c|c|}
\hline \multirow{2}{*}{$\begin{array}{c}\text { Densidade arbórea } \\
\left(\text { árvores.ha }{ }^{-1}\right)\end{array}$} & \multicolumn{3}{|c|}{ Período 1} & \multicolumn{3}{|c|}{ Período 2} \\
\hline & $\begin{array}{c}\text { GMD } \\
\mathrm{kg}^{-1} \cdot \text { animal }^{-1} \cdot \mathrm{dia}^{-1}\end{array}$ & $\begin{array}{c}\text { CA } \\
\text { kg.ha }{ }^{-1}\end{array}$ & $\begin{array}{c}\text { GA } \\
\text { kg.ha }{ }^{-1}\end{array}$ & $\begin{array}{c}\text { GMD } \\
\mathrm{kg}^{-1} \cdot \text { animal }^{-1} \cdot \mathrm{dia}^{-1}\end{array}$ & $\begin{array}{c}\text { CA } \\
\text { kg.ha' }\end{array}$ & $\begin{array}{c}\text { GA } \\
\text { kg.ha-1 }\end{array}$ \\
\hline 833 & $0,637 \mathrm{a}$ & $403 \mathrm{a}$ & $95 \mathrm{a}$ & $769 a$ & $572 \mathrm{a}$ & $134 \mathrm{a}$ \\
\hline 500 & $0,502 \mathrm{~b}$ & $420 \mathrm{a}$ & $79 a$ & $734 \mathrm{a}$ & $611 \mathrm{a}$ & $145 \mathrm{a}$ \\
\hline
\end{tabular}

Médias seguidas por letras diferentes, na coluna, diferem ao nível de 5\% de probabilidade pelo teste de Tukey.

No segundo período, não foram verificadas diferenças significativas para as espécies forrageiras e densidades arbóreas avaliadas (Tabelas 4 e 5), nas variáveis-resposta "ganho médio diário" e "ganho por área". Por outro lado, a carga animal foi superior para capim aruana $(\mathrm{P}<0,05)$, não diferindo da carga de capim pangola, que por sua vez não diferiu significativamente de capim gatton. Não houve diferenças significativas para esta variável entre as densidades arbóreas avaliadas. O capim aruana destacou-se, nas duas avaliações, por suportar cargas animais maiores em relação às outras espécies avaliadas.

Desta forma, é possível afirmar que as densidades de 833 e 500 árvores.ha $^{-1}$ exerceram efeito semelhante sobre o crescimento da pastagem associada. No entanto, Castilhos et al. (1999), ao avaliar em período anterior, na mesma área deste estudo, o desempenho de capim gatton e braquiária nas densidades arbóreas de 1.666 e 1.000 árvores.ha ${ }^{-1}$, constataram menores taxas de crescimento $\mathrm{e}$ disponibilidade de forragem na maior densidade arbórea. As taxas de crescimento observadas foram de 16,7 e $26,7 \mathrm{~kg}$ de matéria seca (MS).ha ${ }^{-1}$, respectivamente, para capim gatton e braquiária, na densidade arbórea de 1.666 árvores. ha $^{-1}$, enquanto que as disponibilidades de forragem foram de 4.047 e $4.315 \mathrm{~kg}$ de $\mathrm{MS} . \mathrm{ha}^{-1}$ para as respectivas pastagens. $\mathrm{Na}$ densidade arbórea de 1.000 árvores.ha ${ }^{-1}$, as taxas de crescimento e disponibilidades de forragem foram, respectivamente, de 28,7 e $65,6 \mathrm{~kg}$ de MS.ha ${ }^{-1}$; 5.989 e $9.359 \mathrm{~kg}$ de MS.ha ${ }^{-1}$, para capim gatton e braquiária.

O sistema silvipastoril avaliado apresentou produtividade animal, em 145 dias de pastejo, variando de 203 a 248 kg.ha-1 de peso vivo, com um desempenho 
animal individual de 0,447 a $0,769 \mathrm{~kg} \cdot \mathrm{animal}^{-1} \cdot \mathrm{dia}^{-1}$.

Silva et al. (1999), trabalhando com animais de sobreano nesta mesma área, em anos anteriores, obtiveram valores de ganho médio diário de $0,644 \mathrm{e}$ 0,696 kg.animal ${ }^{-1}$ e ganho por área de 104 e 169 kg.ha- ${ }^{-1}$, nos piquetes com o capim gatton, nas densidades de 1.666 e 1.000 árvores.ha $^{-1}$, respectivamente. Lucas (2004), em trabalho realizado nessa mesma área deste estudo, não encontrou efeito significativo em relação à densidade arbórea e espécie forrageira. Entretanto, reporta valores mais elevados em relação aos resultados de desempenho animal individual obtidos neste trabalho, sendo que em média sobre os tratamentos, o GMD foi de $0,794 \mathrm{~kg}$.animal ${ }^{-1} \cdot \mathrm{dia}^{-1}$.

Em sistemas silvipastoris, a produtividade animal e a produção do componente arbóreo não devem ser avaliadas isoladamente, pois existem outras características do ponto de vista ecológico, de conservação do solo e da água e sociais, além da sustentabilidade do ecossistema que devem ser levadas em consideração. Calil (2003), durante o desenvolvimento do presente estudo, avaliou a ciclagem de nutrientes no sistema silvipastoril. A autora salientou o importante papel da serrapilheira na manutenção da ciclagem de nutrientes nesse sistema. A serrapilheira acumulada sobre o solo continha 141,9 kg.ha- ${ }^{-1}$ de N; 7,9 kg.ha-1 de P e 26,4 kg.ha-1 de K, aos sete anos de implantação do sistema.

$\mathrm{Na}$ avaliação econômica dos produtos obtidos em SSP, onde a densidade das árvores deve ser menor que o cultivo florestal convencional, deve-se buscar um produto com maior valor agregado. No caso dos animais, deve-se dar ênfase ao desempenho individual, pois quanto maior o GMD, menor a idade de abate.

Após sete anos de avaliação deste sistema, foi possível constatar que o desbaste sistemático, realizado aos cinco anos de idade do componente arbóreo, além de garantir a persistência das espécies forrageiras até o corte das árvores e consequente produção animal, é uma alternativa para antecipação de receita. Ou seja, o produtor pode implantar o sistema com uma densidade arbórea maior, realizar o desbaste e obter renda com a comercialização da madeira, casca e produto animal, antes dos sete anos.

Além disto, foi observado que, em função do intenso sombreamento causado pelas árvores aos quatro anos após o plantio, o capim annoni desapareceu do subbosque. Este capim é uma planta invasora que ocupa uma área de dois milhões de hectares no Rio Grande do
Sul, sendo uma grande ameaça à diversidade florística da pastagem nativa do Bioma Pampa. Como o capim annoni é uma espécie $\mathrm{C} 4$ que não tolera sombreamento, o seu controle poderá ser através do cultivo florestal, sem o uso de agrotóxico. A atividade florestal sendo realizada em área infestada com capim annoni causará menor impacto no Bioma Pampa.

\section{Conclusões}

Densidades arbóreas de acácia-negra iguais ou inferiores a 833 árvores.ha ${ }^{-1}$ reduzem o potencial de máxima produção florestal em favorecimento da produção animal.

As densidades arbóreas de acácia-negra de 833 e 500 árvores.ha ${ }^{-1}$ permitem desempenho animal satisfatório em sistema silvipastoril no Estado do Rio Grande do Sul.

\section{Agradecimentos}

Os autores agradecem o apoio financeiro da Fapergs e da empresa Seta S.A.; ao Dr. Jamir Luis Silva da Silva pela colaboração nas avaliações de campo; aos engenheiros florestais Elias Moreira dos Santos, pelas avaliações do componente arbóreo, e Lauro Beltrão, pelas sugestões na discussão dos resultados de produção florestal. Agradecimento especial aos professores Carlos Nabinger e Luis Mauro Rosa, pelas orientações na compra de equipamentos para avaliação da radiação fotossinteticamente ativa.

\section{Referências}

ABRAF. Anuário estatístico da ABRAF: ano base 2005. Brasília, 2006. 80p.

CLASON, T.R. Silvopastoral practices sustain timber and forage production in commercial loblolly pine plantations of northwest Louisiana, USA. Agroforestry System, Dordrecht, v. 44, p. 293-303, 1999.

CALIL, F. N. Aspectos da ciclagem de nutrientes em um sistema silvipastoril com Acacia mearnsii De Wild., no município de Tupanciretã, RS. Santa Maria, 2003. 77f. Dissertação (Mestrado) - Programa de Pós-Graduação em Engenharia Florestal - Silvicultura, Universidade Federal de Santa Maria, Santa Maria, 2003.

CASTILHOS, Z. M. S; SILVA, J. L. S.; GUTERRES, E; SAVIAN, J. F.; AMARAL, H. R. B.; COSTA, J. A. A.

Desempenho de espécies forrageiras de verão em sistema silvipastoril com acácia-negra (Acacia mearnsii De Wild.). In: Reunião Anual da Sociedade Brasileira de Zootecnia, 36. SBZ. Anais... 26 a 29 de julho, 1999, Porto Alegre, RS. p.15. 1999. 
CRUZ, C. D. PROGRAMA GENES - versão Windows: aplicativo computacional em genética e estatística. Viçosa : UFV, 2001. 648p.

SISTEMA brasileiro de classificação de solos. Brasilia, DF: Embrapa Produção de Informação; Rio de Janeiro: Embrapa Solos, 1999. 412p.

GARCIA, R.; COUTO, L. Sistemas silvipastoris: tecnologia emergente de sustentabilidade. In: SIMPOSIO INTERNACIONAL SOBRE PRODUÇÃO ANIMAL EM PASTEJO, 1997, Viçosa, MG. Anais... Viçosa: UFV. DZO, 1997. p. 447-471.

GARCIA, R.; COUTO, L. Sistemas silvipastoris, Experiências no Estado de Minas Gerais. ln: 11 CONGRESSO BRASILEIRO DE ECONOMIA E PLANEJAMENTO FLORESTAL. Curitiba, PR. Anais... v. 1. 211-219. 1991.

GLUFKE, C.; FINGER, C. A.G.; SCHNEIDER,P. R. Crescimento de Pinus elliottii Engelm. sob diferentes intensidades de desbaste. Ciência Florestal, Santa Maria, v. 7, n. 1, p. 11-25, 1997.

JACQUES, A. V. A.; NABINGER, C. O ecossistema Pastagens Naturais. In: Simpósio de Forrageiras e Produção Animal. Importânica e potencial produtivo da Pastagem nativa. Anais... Porto Alegre, Editora da ULBRA. p. 7-10. 2006.

LUCAS, N. M. Desempenho animal em sistema silvipastoril com acácia-negra (Acacia mearnsii De Wild.) e rendimento de matéria seca de cultivares de Panicum maximum Jacq. sob dois regimes de luz solar. 2004. $127 \mathrm{f}$. Tese (Doutorado em Zootecnia) - Programa de Pós-Graduação em Zootecnia, Faculdade de Agronomia, Universidade Federal do Rio Grande do Sul, Porto Alegre.

MACHADO, F. P. Contribuição ao estudo do clima do Rio Grande do Sul. Rio de Janeiro: Serviço Gráfico do Instituto Brasileiro de Geografia e Estatística, 1950. p. 8-9.

MANTOEFEL, J. C. Reflorestamento no setor privado - Acacicultura. In: SEMINÁRIO SOBRE SITUAÇÃO FLORESTAL DO RIO GRANDE DO SUL, 1, 1991. Anais... Santa Maria: UFSM/CEPEF/FATEC: Secretaria de Agricultura e Abastecimento do Rio Grande do Sul, 1991, p. 108-114.

MELO, J. T. Eucalyptus grandis e Pinus olocarpa consorciado com culturas e pastagens em áreas de cerrado. In: II CONGRESSO BRASILEIRO DE ECONOMIA E PLANEJAMENTO FLORESTAL, 1991, Curitiba, PR. Anais... 1991.v. 1, 95-108.
MORENO, J. A. Clima do Rio Grande do Sul. Porto Alegre: Secretaria da Agricultura. 1961. 41p.

MOTT, G. O.; LUCAS, M. L. The design conduct and interpretation of grazing trials on cultivated and improved pastures. In: INTERNATIONAL GRASSLAND CONGRESS, 6, State College, 1952. Proceedings... Pensylvania, State College press, 1952, p. 1380-1385.

PERI P. L.; MASON E. G.; POLLOCK, K. M.; VARELLA, A. C.; MEAD, D. J. Early growth and quality of radiata pine in a silvopastoral system in New Zealand. Agroforestry System, Dordrecht, v. 55, p. 207-219, 2002.

PASTRELLO, C. P. Anualpec 2006: anuário da pecuária brasileira. São Paulo: Instituto FNP, 2006. 369 p.

SAIBRO, J. C. Animal production from tree-pasture association systems in Brazil. In: INTERNATIONAL GRASSLAND CONGRESS, 19., 2001, São Pedro, SP. Palestra... São Pedro, SP : FEALQ, 2001. p. 637-643.

SCHNEIDER, P. R.; FINGER, C. A. G.; HOPPE, J. M. Efeito da intensidade de desrama na produção de Pinus elliottii Engelm., implantado em solo pobre, no estado do Rio Grande do Sul.

Ciência Florestal, Santa Maria, v. 9, n. 1, p. 35-46, 1999.

SCHNEIDER, P. R.; FLEIG F. D.; FINGER, C. A. G.; KLEIN J. E. M.; Crecimento da acácia-negra, Acacia mearnsii De Wild em diferentes espaçamentos. Ciência Florestal, Santa Maria, v.10, n. 2, p. 101-112, 2000.

SEBRAE - Serviço Brasileiro de Apoio às Micro e Pequenas Empresas; FARSUL - Federação da Agricultura do Rio Grande do Sul; SENAR - Serviço Nacional de Aprendizagem Rural. Diagnóstico de sistemas de produção da bovinocultura de corte do Estado do Rio Grande do Sul: Relatório de pesquisa. Porto Alegre: UFRGS.IEPE, 2005. 265 pp.

SILVA, J. L. S. Produtividade de componentes de um sistema silvipastoril constituído por Eucalyptus saligna Smith e pastagens cultivada e nativa no Rio Grande do Sul. 1998. 178 f. Tese (Doutorado em Zootecnia) - Universidade Federal de Viçosa, Viçosa.

SILVA, J. L. S.; CASTILHOS, Z. M. S.; SAVIAN, J. F.; GUTERRES, E. Desempenho animal e forragem residual em sistema silvipastoril com acácia-negra (Acacia mearnsii De Wild.) e pastagens de verão no RS. In: REUNIÃO ANUAL DA SOCIEDADE BRASILEIRA DE ZOOTECNIA, 36., 1999, Porto Alegre, RS. Resumos... Porto Alegre, RS: UFRGS, 1999. p. 15.

Recebido em 21 de maio de 2009 e aprovado em 19 de dezembro de 2009 
